Research Paper

\title{
Characterization of a Novel Transgenic Mouse Tumor Model for Targeting HER2+ Cancer Stem Cells
}

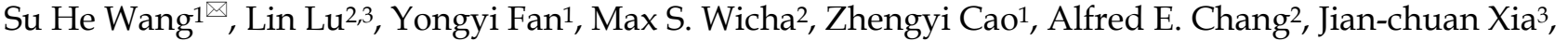 \\ James R. Baker Jr. ${ }^{1}$,Qiao $\mathrm{Li}^{2}{ }^{\bowtie}$ \\ 1. Michigan Nanotechnology Institute for Medicine and Biological Sciences \\ 2. University of Michigan Comprehensive Cancer Center, Ann Arbor, Michigan 48109, USA \\ 3. State Key Laboratory of Oncology in Southern China and Department of Experimental Research, Sun Yat-sen University Cancer Center, \\ Guangzhou 510060, P.R. China
}

$\triangle$ Corresponding author: Dr. Su He Wang (shidasui@umich.edu) or Qiao Li (qiaoli@umich.edu), Phone: 734-615-2205 or 734-615-1977.

( ) Ivyspring International Publisher. This is an open-access article distributed under the terms of the Creative Commons License (http://creativecommons.org/ licenses/by-nc-nd/3.0/). Reproduction is permitted for personal, noncommercial use, provided that the article is in whole, unmodified, and properly cited.

Received: 2013.03.23; Accepted: 2013.10.06; Published: 2013.12.06

\begin{abstract}
HER 2 is an oncogenic tumor-associated antigen overexpressed in $20-25 \%$ of breast cancers, which is associated with increased invasion, metastasis of the disease and resistance to therapy. Recent studies have further shown that HER2 can increase the population of breast cancer stem cells (BCSCs). However, there is currently no in vivo model for the study of HER2 ${ }^{+}$BCSCs. In this study, we characterized a mouse breast cancer model for HER2 ${ }^{+}$BCSCs. This was accomplished by inoculating mouse mammary tumor EO77I cells engineered with human wild-type HER2 (EO77IE2) into C57BL/6 HER2 transgenic mice to test and confirm the stable human HER2 expression in the model. More importantly, we detected a subpopulation of EO77IE2 cells with a high activity of aldehyde dehydrogenases $\left(\mathrm{ALDH}^{\text {high }}\right)$. We demonstrated that the isolated $A L D H^{\text {high }}$ EO77IE2 cells possessed key properties of BCSCs including enhanced tumorigenicity, generation of heterogeneous tumors and the capacity to self-renewal in vitro. In conclusion, the tumors formed in C57BL/6 HER2 transgenic mice with EO77IE2 cell injection revealed stable and functional human HER2 expression. These tumors contain a subset of ALDH high cells which are small in number, but are enriched in cancer stem cells. This model is deemed to be useful for experiments aimed to develop novel treatments to target HER2 ${ }^{+}$BCSCs.
\end{abstract}

Key words: HER2, breast cancer, cancer stem cells, mouse model, antitumor immunity.

\section{Introduction}

Despite recent advances in diagnosis and treatment, breast cancer remains a leading cause of cancer death in women in the United States. The high mortality of this malignancy is mainly due to the resistance to current treatments, e.g. chemotherapy and radiation therapy, as well as the metastasis and recurrence of the disease. In order to improve the therapeutic efficacy, relevant animal models are needed and are critical for the development of novel treatment protocols against this disease.

It is well-understood that human breast cancer is a highly heterogeneous disease, with $20-25 \%$ of breast cancers characterized by the over-expression of human epidermal growth factor receptor 2 (HER2) (1). It has been demonstrated that the over-expression of HER2 contributes to mammary carcinogenesis, and promotes invasion and metastasis of breast cancer. HER2 is also recognized as a pathological biomarker that distinguishes cancer and non-cancer breast cells, since the expression of HER2 protein on the surface of HER2+ breast cancer cells can be 50-100 fold higher than normal cells. Importantly, this biological property of HER2 has made it an ideal molecule for the target therapy against HER2+ breast cancers (1). In- 
deed, Herceptin (trastuzumab), a humanized monoclonal antibody against HER2, is currently the most effective adjuvant treatment for HER2 ${ }^{+}$breast cancers $(1,2)$. However, despite the success of Herceptin, resistance to the treatment occurs in a significant number of patients positive for HER2, contributing to the high mortality rate of breast cancers.

Recent studies have shown that the level of aldehyde dehydrogenases (ALDHs) in HER2 ${ }^{+}$breast cancer is much higher than that in HER2- breast cancers $(2,3)$. ALDHs are a group of enzymes responsible for the oxidation of aldehydes to their corresponding carboxylic acids. High ALDH activity is associated with metastasis, resistance to chemotherapies, and poor prognosis in human breast cancer, and has been identified as a marker of human breast cancer stem cells (BCSCs) (4-7). Importantly, high levels of ALDEFLUOR/ALDH have been used to isolate cancer stem cell (CSC)-enriched populations in various tumor types by multiple investigators (8-15), including our own group. Isolation and characterization of CSCs in animal breast cancers may provide models and opportunities for the development of novel treatment options for human breast cancers.

Human breast cancer has multiple distinctive features, which can be used to divide this malignancy into several subsets that are genetypically, phenotypically and behaviorally different. Some of these features may overlap; technically it is impossible to have a single experimental model to display multiple features of this complex human disease. Therefore, a number of experimental models need to present the whole picture of human breast cancer, with each model to address one or a few particular features. In this study, we established a mouse breast cancer model for human HER2 ${ }^{+}$breast cancer by implanting mouse mammary tumor EO771 cells engineered with human wild-type HER2 into C57BL/6 HER2 transgenic mice. In this model, we isolated ALDH high cell populations from the HER2-expressing E0771 cells, and demonstrated their CSC nature versus the ALD$\mathrm{H}^{\text {low }}$ cells isolated from the same HER2-expressing E0771 cells. This may represent a unique mouse model of breast cancer with stable human HER2 expression and a subpopulation of ALDH high CSCs. This model will be useful for efforts aimed at the development of new treatments to target HER2 ${ }^{+}$BCSCs.

\section{Materials and METHODS}

\section{Cell culture and xenograft in mice}

EO771 cells were provided by Dr. Daniel Allendorf (Louisville, KY). They were derived from a mammary cancer of C57BL/6 mouse (16), and were stably transfected with the full-length human HER2
cDNA to express the human HER2 antigen (EO771E2 cells). EO771 and EO77E2 cells were cultured in DMEM media with 10\% FBS. For xenograft, different concentrations of EO771E2 cells were inoculated into the flank of 6-week old C57BL/6 HER2 transgenic mice (Jackson Laboratory, Bar Harbor, Maine). These mice were transgenically modified to express the HER2 proto-oncogene (ERBB2) causing the overexpression of the HER2 surface protein (CD340). The status of transgenicity in the mice was evaluated via DNA isolation and q-PCR with the forward primer (GAG CCG CGA GCA CCC A) and reverse primer (GGT GGG CAG GTA GGT GAG TCC C), respectively. The tumor growth was monitored twice per week by measuring the size of the tumor.

\section{HER2 detection}

Expression of human HER2 protein on the surface of EO771E2 cells was determined by flow cytometer using an anti-HER2 monoclonal antibody (Trastuzumab, Genentech, Inc, San Francisco, CA). PE-conjugated mouse anti-human Ig $\kappa$ light chain (BD pharmingen) was used as a second antibody.

\section{Detection of ALDH high EO77IE2 cells}

The activity of ALDH was measured by a fluorogenic dye-based ALDEFLUOR assay kit (StemCell Technologies, Vancouver, BC) with or without the specific ALDH inhibitor diethylaminobenzaldehyde (DEAB). The assay is based on the principle that ALDH can convert uncharged ALDH-substrate, BAAA (BODIPY, aminoacetaldehyde), into a negatively charged reaction product BAA (BODIPY, aminoaccetate), which is fluorescent and retained inside the cells. Therefore, the higher levels of ALDH enzymatic activity, the more brightly cells will be stained. The fraction of cells with ALDH activity labeled by ALDEFLUOR was measured with a flow cytometer. In each experiment, a sample of cells was treated under identical conditions with $50 \mathrm{mM}$ of the ALDH inhibitor DEAB to serve as a control for gating. Based on the activity of ALDH, EO771E2 cell were sorted into $\mathrm{ALDH}^{\text {high }}$ and $\mathrm{ALDH} \mathrm{H}^{\text {low }}$ E0771E2 cells as we previously described (15). 7-AAD is used to discriminate live cells from dead cells which were excluded based on light scatter characteristics.

\section{Tumorigenicity of ALDH ${ }^{\text {high }}$ and ALDH low E077IE2 cells}

The capability of $\mathrm{ALDH}^{\text {high }}$ and $\mathrm{ALDH}^{\text {low }}$ E0771E2 cells to form tumors was examined by inoculating freshly isolated $\mathrm{ALDH}^{\text {high }}$ and $\mathrm{ALDH}^{\text {low }}$ EO771E2 cells into C57BL/6 HER2 transgenic mice. Briefly, equal numbers of sorted ALDH high or ALD$\mathrm{H}^{\text {low }}$ cells were respectively mixed with Matrigel (BD 
Biosciences) at the ratio of cell:matrigel $=1: 1$ and injected into the opposite side of the same C57BL/ 6 HER2 transgenic mice to test their tumorigenicity on developing xenografts. The growth of tumor was monitored twice per week by measuring the size of the tumor.

\section{Isolation of ALDH ${ }^{\text {high }}$ E077 IE2 cells from the tumors formed from the initial ALDH high E077 IE2 cell injection}

The existing of ALDHigh E0771E2 cell population in mouse tumors formed by the injection of ALDH ${ }^{\text {high }}$ E0771E2 cells was assessed using freshly harvested tumor tissues from the C57BL/6 HER2 transgenic mice. Briefly, the tumor was harvested from mice implanted with ALDH ${ }^{\text {high }}$ EO771E2 cells when the tumor mass reached to the size of $30 \mathrm{~mm}^{2}$. The harvested tumor tissues were immediately preceded for the digestion to isolate single tumor cells. After digestion, the tumor cells were sorted into $\mathrm{ALDH}^{\text {high }}$ and $\mathrm{ALDH}^{\text {low }}$ populations as described above in the initial detection of ALDH ${ }^{\text {high }}$ EO771E2 cells. Then equal numbers of sorted ALDH high or $\mathrm{ALDH}^{\text {low }}$ cells were cultured in vitro to test whether they could form spheres to verify their stemness.

\section{Mammosphere culture}

$\mathrm{ALDH}^{\text {high }}$ or $\mathrm{ALDH}^{\text {low }}$ EO771E2 cells were plated
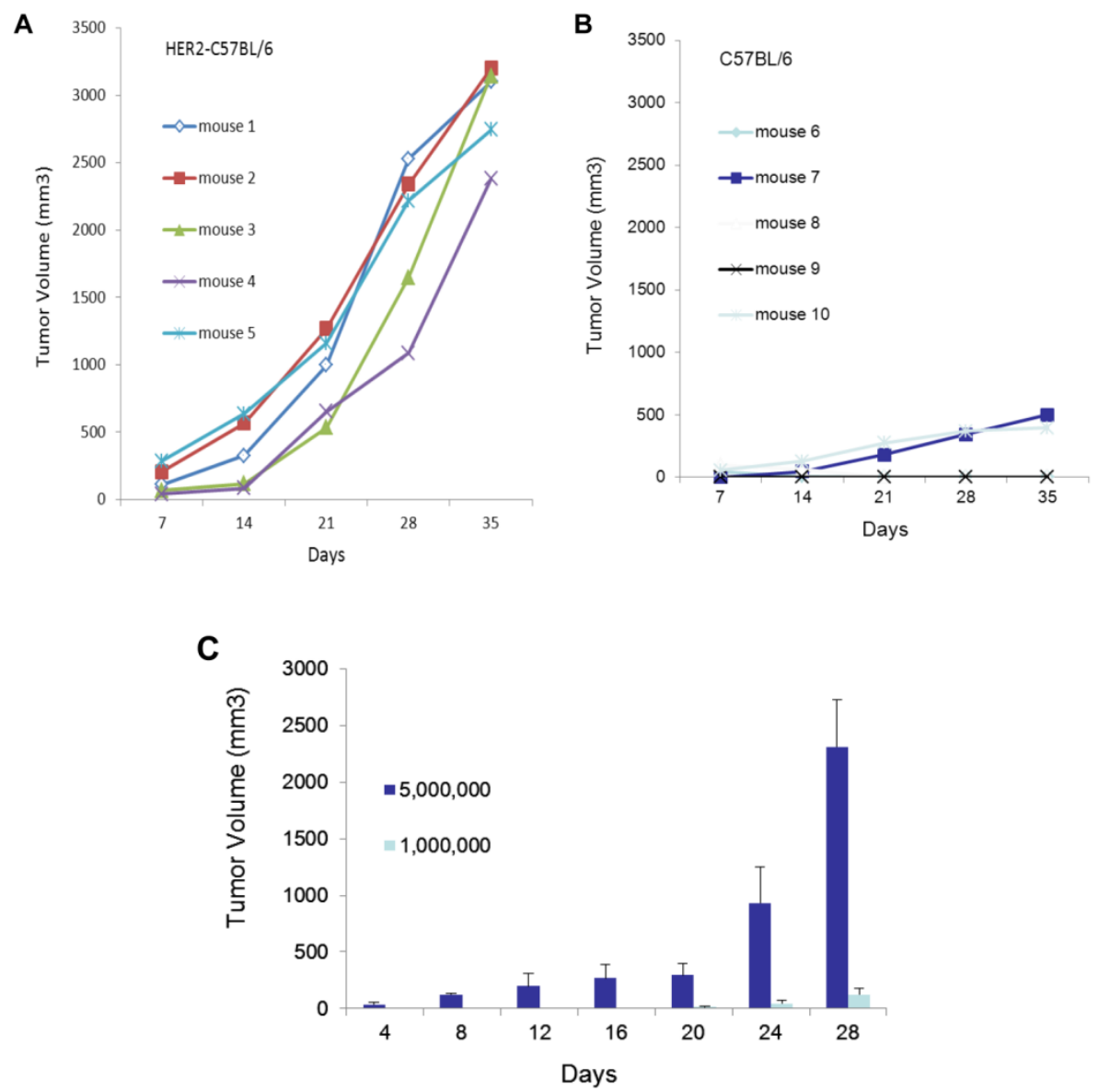

in ultra-low attachment plates (Costar, Corning, NY) in serum-free CSC medium. Mammosphere was observed under the Nikon inverted microscope (Nikon Eclipse Ti-U).

\section{Statistical analysis}

Statistical analyses were performed using the Statistics Package for Social Sciences (SPSS for Windows, version 13.0, SPSS Inc, Chicago, IL). One-way ANOVA was used to compare means of three or more samples. t-test was used to compare the means of two variables. $\mathrm{P}$ values of less than 0.05 were considered statistically significant.

\section{RESULTS}

\section{Establishment of EO77IE2 xenografts in C57BL/6 HER2 transgenic mice}

In HER2 transgenic mice, the human HER2 transgene is recognized as a self-antigen, to which the host is tolerant. Therefore, the introduction of human HER2-expressing cells, EO771E2, does not provoke a significant immune response in these mice, and tumors are expected to grow more aggressively in HER2 transgenic mice than in the non-transgenic control. Consistent with this, we observed that $2 \times 10^{6}$ EO771E2 cells subcutaneously injected into C57BL/6 HER2 transgenic mice (Figure 1A) produced tumors of significantly larger size than an equal number of EO771E2 cells injected into the wild-type C57BL/6 mice (Figure 1B; $(p<0.005)$. We also compared tumor growth when $5 \times 10^{6}$ or $1 \times 10^{6}$ EO771E2 cells were subcutaneously injected into C57BL/ 6 HER2 transgenic mice, and observed that the growth of tumors was in a cell concentration and time -dependent manner (Figure 1C).

Figure I: Growth of EO77IE2 cells in mice. $2 \times 10^{6}$ of EO77IE2 cells were subcutaneously injected into the C57BL/6 HER2 transgenic mice $(\mathbf{A}, \mathrm{n}=5)$ and wild-type C57BL/6 mice $(\mathbf{B}, \mathrm{n}=5)$. Tumor size was measured weekly for 5 weeks, and tumor growth curves were constructed to compare the size of tumor between these two groups $(p<0.005)$. In C, $5 \times 10^{6}$ or $1 \times 10^{6}$ of EO77IE2 cells were subcutaneously injected into the C57BL/6 HER2 transgenic mice, respectively. Tumor was measured every 4 days. The average tumor size is shown $(n=6, p<0.005)$. 


\section{Expression of HER2 in E077 IE2 cells}

The expression of human HER2 in E0771E2 cells was examined by flow cytometry and immunohistochemistry. While the cultured parental E0771 cells were negative for HER2 staining (Figure 2A), approximately $96 \%$ of cultured E0771E2 cells expressed HER2 protein as identified by the anti-human HER2 monoclonal antibody (Figure 2C). There is little overlapping between the response curves of both reactions (Figure 2B), confirming total difference of these two cell lines in terms of HER2 expression. The expression of HER2 in E0771 cells vs. E0771E2 cells was also demonstrated directly by immunohistochemistry staining followed by fluorescence microscopy (Figure 2D \& 2E) respectively.

\section{Identification of the an ALDH high sub-population in E077IE2 cells}

To identify ALDEFLUOR ${ }^{+} / \mathrm{ALDH}^{\text {high }}$ cells in these human HER2-expressing cells, E0771E2 cells were subjected to ALDEFLUOR assay to measure the activity of the ALDH. We observed a very small percentage of ALDEFLUOR ${ }^{+} / \mathrm{ALDH}^{\text {high }}$ cells in the cultured E0771E2 cells based on the high activity of ALDH, which was sensitive to DEAB inhibition (Figure 3). All cells tested showed some ALDH activity, with the majority of cells demonstrating a moderate level of ALDH compared with the control in the presence of $\mathrm{DEAB}$, and a minority showing either low or high ALDH activity. In comparison with the control population, the population with high ALDH activity was observed in approximately $6.5 \%$ of the total cultured E0771E2 population. Similar analysis demonstrated that the population with low ALDH levels comprised approximately $7 \%$ of the total. Cells with high ALDH activity (6.5\%) and the low ALDH activity $(7 \%)$ were then isolated and designated as $\mathrm{ALDH}^{\text {high }}$ and ALDH ${ }^{\text {low }}$, respectively, in the subsequent experiments.
A

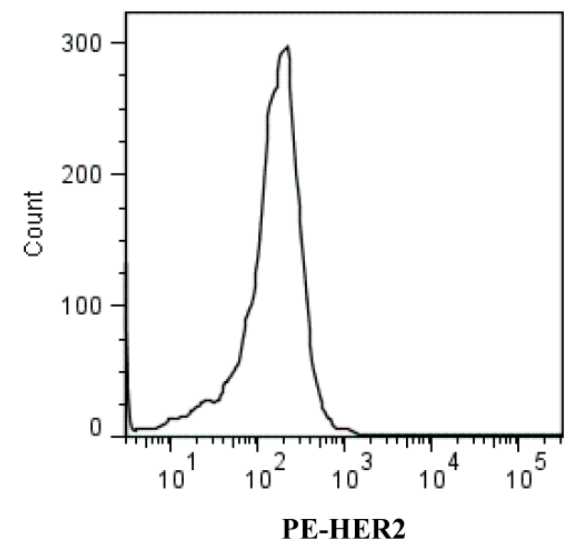

B

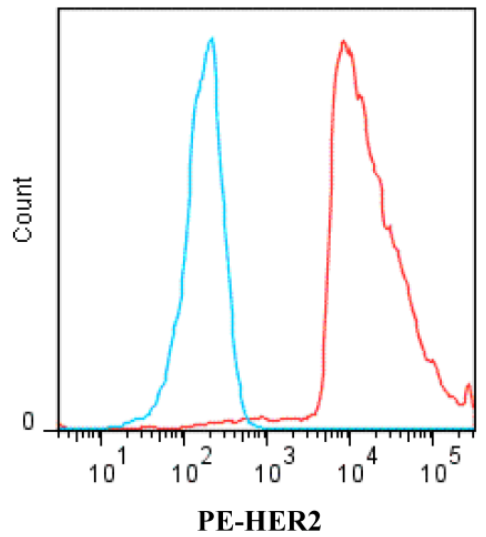

C

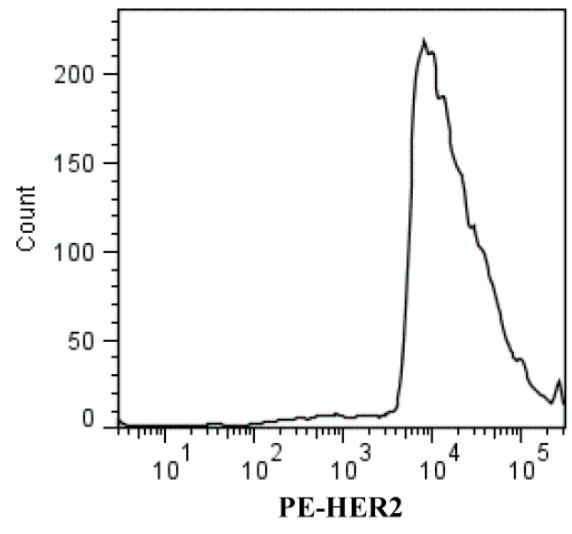

D

\section{E}
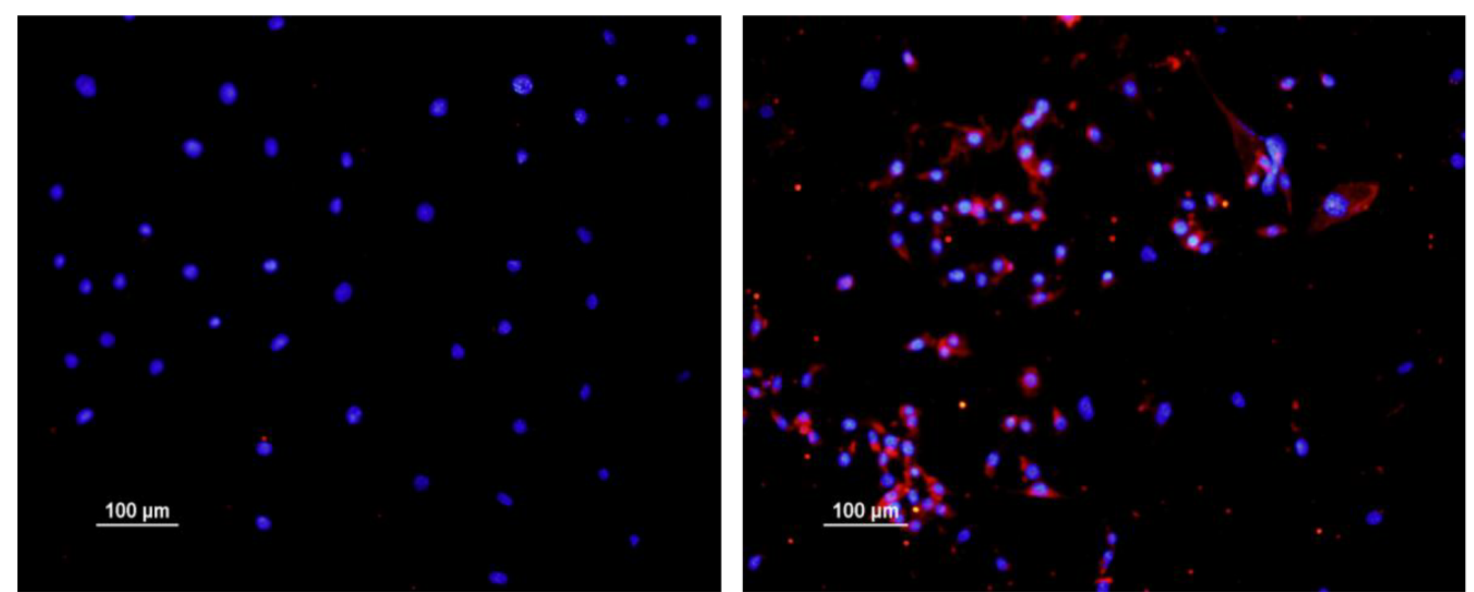

Figure 2: Expression of HER2 in EO77IE2 cells. Expression of human HER2 protein on the EO77IE2 cell surface was examined by flow cytometer and immunohistochemistry using a monoclonal antibody against human HER2. HER2 fluorescence for E077IE2 cells with both primary and second antibodies is plotted along the $\mathrm{x}$-axis, on log scale (C). The fluorescence for EO77I cells with both primary and second antibodies is plotted in A. A combined image shows high level of HER2 expression in EO77IE2 cells, but not in EO77I cells (B). Immunofluorescent staining of cultured EO77IE2 cells is shown in D \& E. Merged DAPI and PE-HER2 staining: E077I cells (D) and EO77IE2 cells (E). 

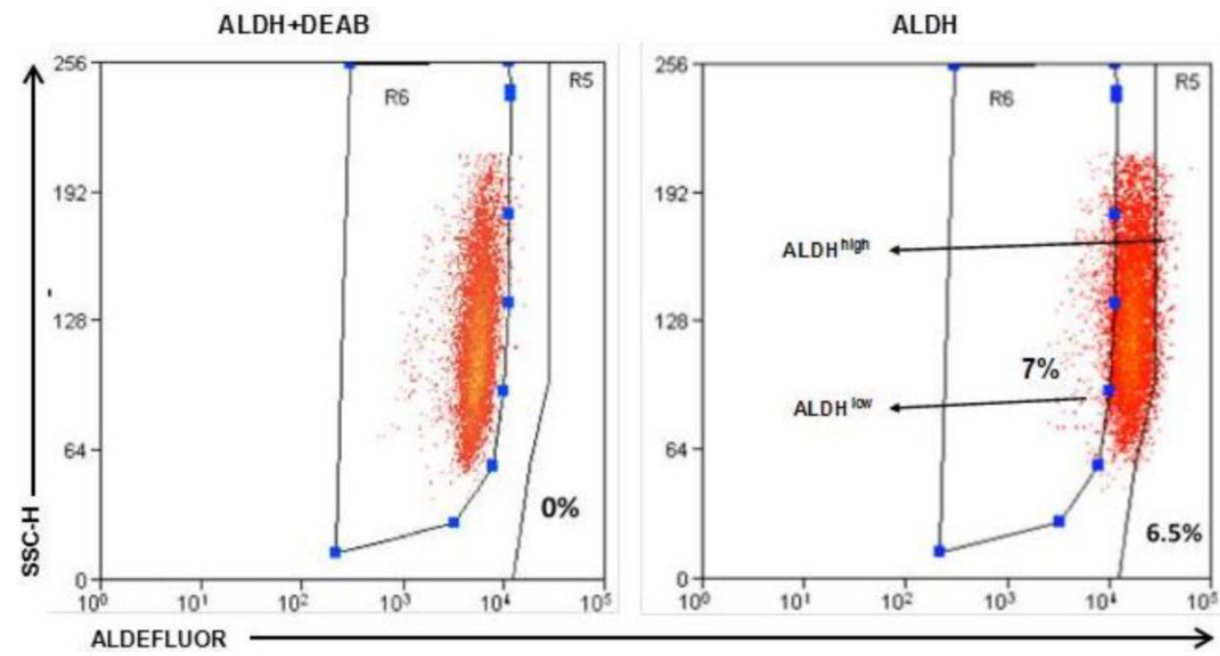

Figure 3: Identification of the ALDH ${ }^{\text {high }}$ and the ALDH ${ }^{\text {low }}$ cell populations. EO77IE2 cells were subjected to ALDEFLUOR assay to measure the activity of ALDH. The same set of the sample treated with ALDH inhibitor DEAB was used as a control (the left panel). ALDH ${ }^{\text {low }}$ and $A L D H^{\text {high }}$ cells were isolated as indicated on the right panel (arrows).
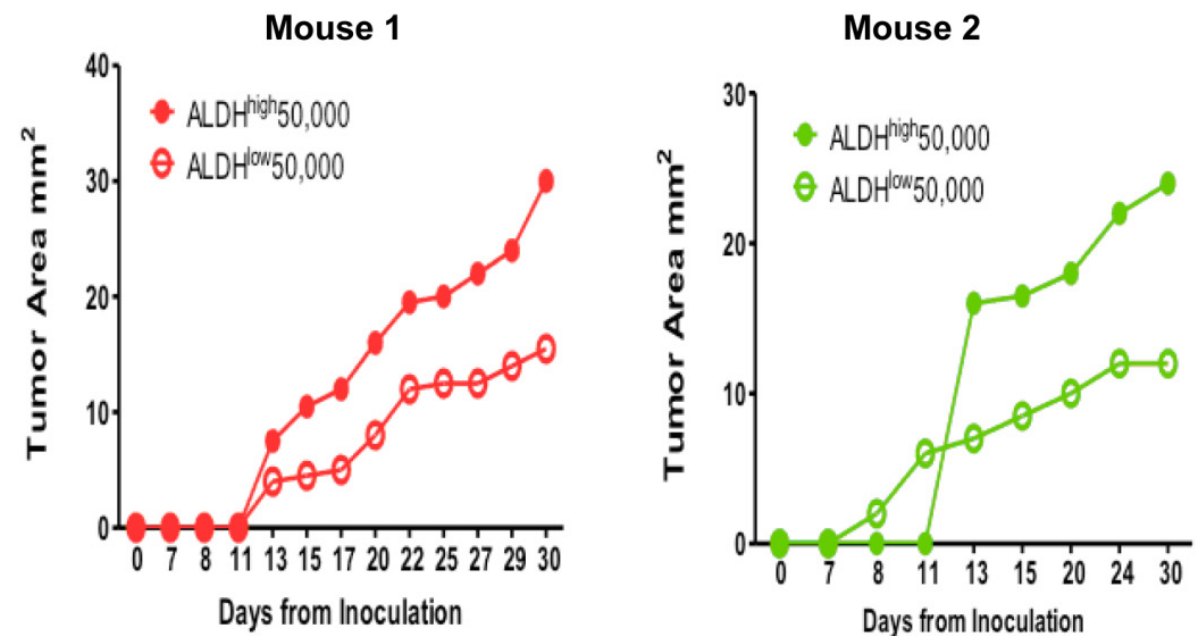

Figure 4: Tumorigenicity of ALDH ${ }^{\text {high }}$ vs. ALDH ${ }^{\text {low }}$ EO77IE2 cells. Equal numbers $(50,000)$ of $A L D H^{\text {high }}$ and $A L D H^{\text {low }}$ cells isolated from cultured EO77IE2 cells were inoculated into the opposite side of the same C57BL/6 HER2 transgenic mice. The growth of tumor was monitored twice per week by measuring the size of tumor. The growth curves were then generated using the size of the tumor against the days monitored.

\section{Tumorigenicity of the ALDHhigh E077 IE2 cells}

To test our hypothesis that the ALDH high E0771E2 tumor cells were enriched for the phenotype of cancer stem cells, we injected the isolated ALDH high and $\mathrm{ALDH}^{\text {low }}$ cell populations subcutaneously into the opposite flanks of the same individual C57BL/ 6 HER2 transgenic mice. Figure 4 showed the growth of tumors from the injected ALDH high and ALDH ${ }^{\text {low }}$ cells isolated from the cultured E0771E2 cells in 2 mice. After the injections, the tumor mass appeared in mice received either the $\mathrm{ALDH}^{\text {high }}$ or the $\mathrm{ALDH}^{\text {low }}$ cells (Figure 4). However, the size of tumor generated from the ALDH ${ }^{\text {high }}$ cells was significantly larger than that generated from the ALDH ${ }^{\text {low }}$ cells in 2 of the 2 mice. It appeared that the longer the period was monitored, the greater the difference between the ALD$\mathrm{H}^{\text {high-formed }}$ xenograft and the ALDH ${ }^{\text {low }}$-formed xenograft was. These experiments suggest that the
ALDH ${ }^{\text {high }}$ E0771E2 tumor cells are much more tumorigenic than the ALDH ${ }^{\text {low }}$ E0771E2 cells.

\section{Presence of the ALDHigh cells in the tumor formed by ALDH ${ }^{\text {high }}$ cell injection}

We harvested the tumor formed from the ALD$\mathrm{H}^{\text {high }}$ cell injection as shown in Figure 4, and detected the existence of the ALDH ${ }^{\text {high }}$ cells using flow cytometry (Figure 5A). We then tested whether isolated ALDH high $(2.7 \%)$ or $\mathrm{ALDH}^{\text {low }}$ cells $(5 \%)$ are capable of tumor sphere formation, since the ability to form spherical aggregates when cultured under non-adherent conditions is a characteristic of cancer stem cells (17). Isolated ALDH ${ }^{\text {high }}$ and $\mathrm{ALDH}^{\text {low }}$ cells were cultured in ultra low attachment plates for 12 days. We observed that the ALDH ${ }^{\text {high }}$ cells formed significantly more tumor spheres than the ALDH ${ }^{\text {low }}$ cells (Figure 5B). 

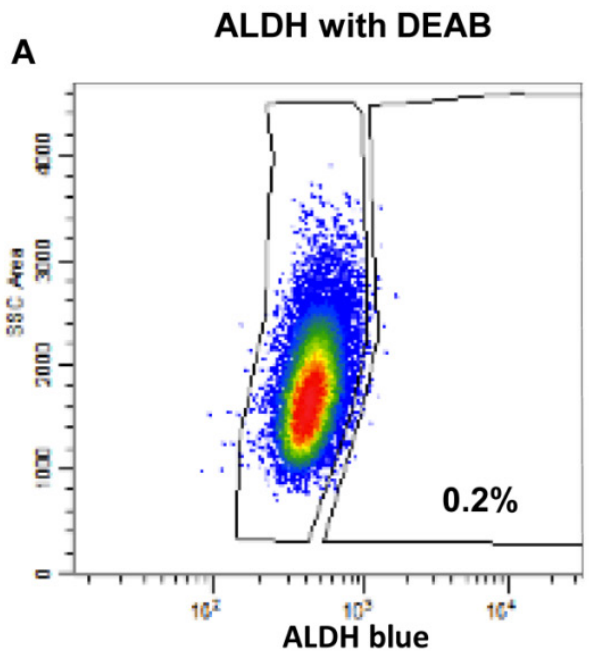

B

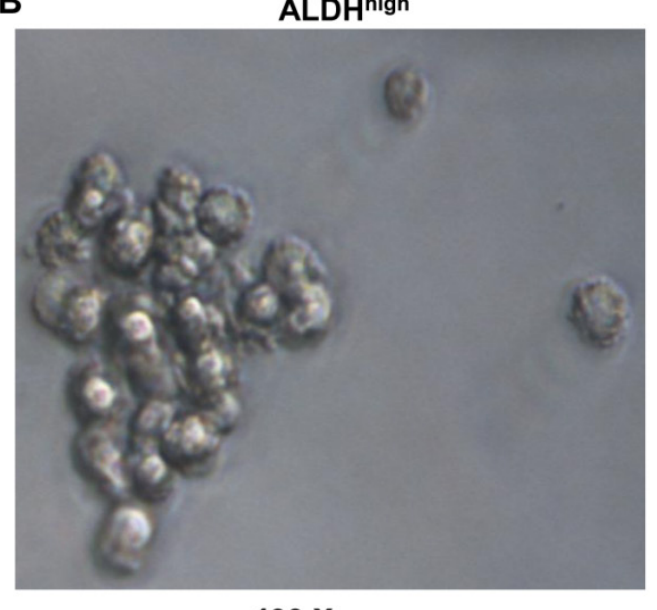

$400 X$

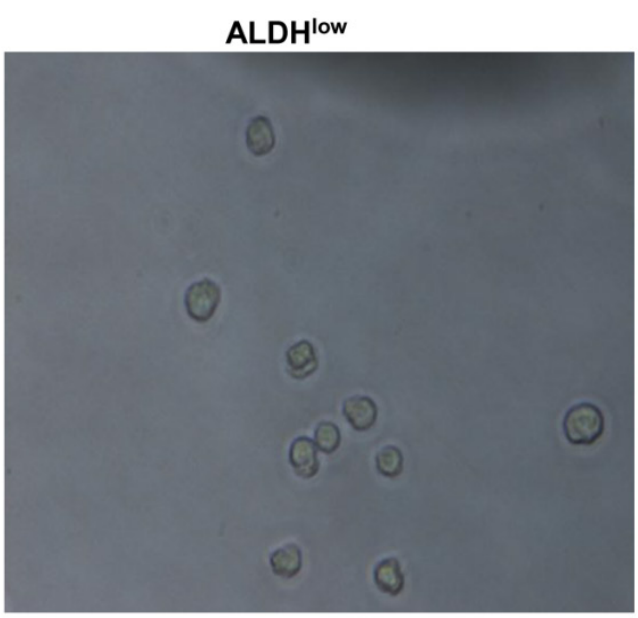

$400 X$

Figure 5: Presence of ALDH ${ }^{\text {high }}$ cells in the mouse tumor and their ability to form spheres. The xenograft formed by the injection of ALDHigh EO77IE2 cells was resected from mice. The resected tumor tissues were digested to prepare single tumor cell suspensions. The isolated tumor cells were then subjected to ALDEFLUOR assay to measure the activity of ALDH as in Fig 3. The percentage of ALDH ${ }^{\text {high }}(2.7 \%)$ and ALDH ${ }^{\text {low }}$ (5.0\%) EO77IE2 cells was shown (Fig 5A). These isolated $\mathrm{ALDH}^{\text {high }}$ or $\mathrm{ALDH}^{\text {low }}$ cells were plated in ultra-low attachment plates in serum-free CSC medium. Spheres were then observed under the microscope (Fig 5B).

\section{DISCUSSION}

The HER2 ${ }^{+}$breast cancer model established in the current work is based on a cell line from a murine breast adenocarcinoma (EO771) transfected with the human HER2 gene (EO771E2) used in the HER2 transgenic C57BL/ 6 mice. One significant advantage of this mouse model is the stable expression of human HER2 in the tumor mass without potential host immune attack against this human protein, because human HER2 is recognized as a self-antigen in the C57BL/6 HER2 transgenic mice (18). While this mouse model does not mount an immune response to human HER2, it is otherwise normal, with an intact immune surveillance system. Marked expression of HER2 was detected in lactation-active mammary ep- ithelium and noticeable expression was also detected constitutively in some other organs of the C57BL/ 6 HER2 transgenic mice (data not shown). These mice have a healthy and normal life span without spontaneous tumor growth (18). Therefore, unlike nude mouse models, the macro- and micro-environment of tumor growth in this established mouse model remains in a natural and normal condition. These features create an ideal experimental situation in which HER2 ${ }^{+}$tumor cells will naturally grow and can be biologically targeted in a physiologically relevant way that mimics the targeting of HER2 ${ }^{+}$tumor cells in patients. Using this model, we demonstrated that E0771E2 cells are able to grow and form a tumor mass in C57BL/ 6 HER2 transgenic mice. On the other hand, EO771E2 tumor growth is inhibited in the wild-type 
C57BL/6 mice, confirming that EO771E2 cells carry functional human HER2 protein.

BCSCs are thought to play a critical factor in breast-tumorigenesis $(2,3)$ as well as breast cancer invasion, metastasis, and the development of resistance to therapeutic treatments (4-6). To identify the potential to isolate and study BCSCs in our model, we analyzed the activity of ALDH in cultured EO771E2 cells, as well as in tumor cells isolated from the mouse xenograft tissues formed after ALDH ${ }^{\text {high }}$ EO771E2 cell injection. We used high levels of ALDEFLUOR/ALDH as a marker to isolate BCSC-enriched populations (8-14). Based on the level of the ALDH activity, three pooled cell subsets were identified. The majority of cells show a moderate level of ALDH. Two minor populations of cells display either a high level of the ALDH activity (ALDH ${ }^{\text {high }}$ ) or a low level of the ALDH activity (ALDH $\left.{ }^{\text {low}}\right)$. Increasing evidence has indicated that ALDH high tumor cells possess the property of cancer stem cells including enhanced tumorigenicity, the capacity for self-renewal/differentiation and the ability to generate a heterogeneous population (7-9). The subset of $\mathrm{ALDH}^{\text {high }}$ cells identified in this model appears to fulfill the requirement of CSCs. Firstly, the isolated $\mathrm{ALDH}^{\text {high }}$ cells are much more tumorigenic than the isolated $\mathrm{ALDH}^{\text {low }}$ cells when inoculated into mice. Secondly, the isolated ALDH ${ }^{\text {high }}$ cells can form tumors comprised of heterogeneous cell populations. Tumors formed by the $\mathrm{ALDH}{ }^{\text {high }}$ cells isolated from cultured EO771E2 cells reproduced three subpopulations of tumor cells, and the ratio of these three subpopulations is similar to that observed in the initial EO771E2 cells. Finally, the isolated ALDH ${ }^{\text {high }}$ cells generate significantly more tumor spheres than the ALDH ${ }^{\text {low }}$ cells, confirming the stemness of the isolated ALD$\mathrm{H}^{\text {high }}$ cells.

Recent studies demonstrate that HER2 over-expression leads to an increase in the CSC-enriched population that contributes to mammary tumorigenesis and invasion in human (1-3). Furthermore, CSCs with HER2 overexpression may change their response to anti-tumor treatments (19-21). These studies have emphasized the significant impact of HER2 on the regulation of BCSC generation and function. They also imply the possibility of using specific HER2-drived protocols to treat and/or prevent breast cancers positive for HER2 by targeting the CSCs. To this end, the development of a biologically relevant animal model that can be used to target HER2 and CSCs simultaneously is critical, and is needed with urgency. The mouse model described herein appears to meet with such a demand.

\section{Acknowledgement}

The work described in this paper was partially supported by Comprehensive Cancer Center, University of Michigan and in part by the Gillson Longenbaugh Foundation.

\section{Competing Interests}

The authors have declared that no competing interest exists.

\section{References}

1. Arteaga CL, Sliwkowski MX, Osborne CK, Perez EA, Puglisi F, Gianni L. Treatment of HER2-positive breast cancer: current status and future perspectives. Nat Rev Clin Oncol. 2011 Nov 29;9(1):16-32. doi: 10.1038/nrclinonc.2011.177.

2. Duru N, Fan M, Candas D, Menaa C, Liu HC, Nantajit D, Wen Y, Xiao K, Eldridge A, Chromy BA, Li S, Spitz DR, Lam KS, Wicha MS, Li JJ. HER2-associated radioresistance of breast cancer stem cells isolated from HER2-negative breast cancer cells. Clin Cancer Res. 2012 Dec 15;18(24):6634-47.

3. Korkaya H, Paulson A, Iovino F, Wicha MS. HER2 regulates the mammary stem/progenitor cell population driving tumorigenesis and invasion. Oncogene. 2008 Oct 16;27(47):6120-30.

4. Tanei T, Morimoto K, Shimazu K, Kim SJ, Tanji Y, Taguchi T, Tamaki Y, Noguchi S. Association of breast cancer stem cells identified by aldehyde dehydrogenase 1 expression with resistance to sequential Paclitaxel and epirubicin-based chemotherapy for breast cancers. Clin Cancer Res. 2009 Jun 15;15(12):4234-41.

5. Charafe-Jauffret E, Ginestier C, Iovino F, Tarpin C, Diebel M, Esterni B, Houvenaeghel G, Extra JM, Bertucci F, Jacquemier J, Xerri L, Dontu G, Stassi G, Xiao Y, Barsky SH, Birnbaum D, Viens P, Wicha MS. Aldehyde dehydrogenase 1-positive cancer stem cells mediate metastasis and poor clinical outcome in inflammatory breast cancer. Clin Cancer Res. 2010 Jan 1;16(1):45-55.

6. Marcato P, Dean CA, Pan D, Araslanova R, Gillis M, Joshi M, Helyer L, Pan L, Leidal A, Gujar S, Giacomantonio CA, Lee PW. Aldehyde dehydrogenase activity of breast cancer stem cells is primarily due to isoform ALDH1A3 and its expression is predictive of metastasis. Stem Cells. 2011 Jan;29(1):32-45.

7. Kim RJ, Park JR, Roh KJ, Choi AR, Kim SR, Kim PH, Yu JH, Lee JW, Ahn SH, Gong G, Hwang JW, Kang KS, Kong G, Sheen YY, Nam JS. High aldehyde dehydrogenase activity enhances stem cell features in breast cancer cells by activating hypoxia-inducible factor-2a. Cancer Lett. 2012; doi: 10.1016/j.canlet.2012.11.026.

8. Tirino V, Desiderio V, Paino F, De Rosa A, Papaccio F, La Noce M, Laino L, De Francesco F, Papaccio G. Cancer stem cells in solid tumors: an overview and new approaches for their isolation and characterization. FASEB J. 2013 Jan;27(1):13-24.

9. Marcato P, Dean CA, Giacomantonio CA, Lee PW. Aldehyde dehydrogenase: its role as a cancer stem cell marker comes down to the specific isoform. Cell Cycle. 2011 May 1;10(9):1378-84.

10. Charafe-Jauffret E, Ginestier C, Iovino F, Tarpin C, Diebel M, Esterni B, Houvenaeghel G, Extra JM, Bertucci F, Jacquemier J, Xerri L, Dontu G, Stassi G, Xiao Y, Barsky SH, Birnbaum D, Viens P, Wicha MS. Aldehyde dehydrogenase 1-positive cancer stem cells mediate metastasis and poor clinical outcome in inflammatory breast cancer. Clin Cancer Res. Jan 2010;16(1):45-55.

11. Awad O, Yustein JT, Shah P, Gul N, Katuri V, O'Neill A, Kong Y, Brown ML, Toretsky JA, Loeb DM. High ALDH activity identifies chemotherapy-resistant Ewing's sarcoma stem cells that retain sensitivity to EWS-FLI1 inhibition. PLoS One. 2010;5(11):e13943.

12. Kim MP, Fleming JB, Wang H, Abbruzzese JL, Choi W, Kopetz S, McConkey DJ, Evans DB, Gallick GE. ALDH activity selectively defines an enhanced tumor-initiating cell population relative to CD133 expression in human pancreatic adenocarcinoma. PLoS One. 2011;6(6):e20636.

13. Wang L, Park P, Zhang H, La Marca F, Lin CY. Prospective identification of tumorigenic osteosarcoma cancer stem cells in OS99-1 cells based on high aldehyde dehydrogenase activity. Int J Cancer. 2011;128(2):294-303.

14. Visus C, Wang Y, Lozano-Leon A, Ferris RL, Silver S, Szczepanski MJ, Brand RE, Ferrone CR, Whiteside TL, Ferrone S, DeLeo AB, Wang X. Targeting ALDH(bright) human carcinoma-initiating cells with ALDH1A1- specific CD8 $^{+}$T cells. Clin Cancer Res 2011; 17:6174-6184.

15. Ning N, Pan $Q$, Zheng F, Teitz-Tennenbaum S, Egenti M, Yet J, Li M, Ginestier C, Wicha MS, Moyer JS, Prince ME, Xu Y, Zhang XL, Huang S, Chang AE, Li Q. Cancer stem cell vaccination confers significant antitumor immunity. Cancer Res. 2012 Apr 1;72(7):1853-64

16. de Zoeten E, Carr-Brendel V, Markovic D, Taylor-Papadimitriou J, Cohen EP. Treatment of breast cancer with fibroblasts transfected with DNA from breast cancer cells. J Immunol. 1999 Jun 1;162(11):6934-41.

17. Cioce M, Gherardi S, Viglietto G, Strano S, Blandino G, Muti P, Ciliberto G. Mammosphere-forming cells from breast cancer cell lines as a tool for the 
identification of CSC-like- and early progenitor-targeting drugs. Cell Cycle. 2010 Jul 15;9(14):2878-87.

18. Piechocki MP, Ho YS, Pilon S, Wei WZ. Human ErbB-2 (Her-2) transgenic mice: a model system for testing Her-2 based vaccines. J Immunol. 2003 Dec 1;171(11):5787-94.

19. Magnifico A, Albano L, Campaner S, Delia D, Castiglioni F, Gasparini P, Sozzi G, Fontanella E, Menard S, Tagliabue E. Tumor-initiating cells of HER2-positive carcinoma cell lines express the highest oncoprotein levels and are trastuzumab sensitive. Clin Cancer Res 2009; 15:2010-21.

20. Singh JK, Farnie G, Bundred NJ, Simões BM, Shergill A, Landberg G, Howell SJ, Clarke RB. Targeting CXCR1/2 Significantly Reduces Breast Cancer Stem Cell Activity and Increases the Efficacy of Inhibiting HER2 via HER2-Dependent and -Independent Mechanisms. Clin Cancer Res. 2013 Feb 1;19(3):643-56.

21. Kanojia D, Zhou W, Zhang J, Jie C, Lo PK, Wang Q, Chen H. Proteomic profiling of cancer stem cells derived from primary tumors of HER2/Neu transgenic mice. Proteomics. 2012 Nov;12(22):3407-15 